$\underline{\text { Research article }}$

\title{
Bacteria mediated silver nanoparticles: comparison as potent antibiofilm agents
}

\author{
M Peiris $^{1}$, N Fernando ${ }^{1}$, P Jayaweera ${ }^{2}$, M Weerasekera $^{1}$, \\ C Gunasekara ${ }^{1,3}$ \\ Sri Lankan Journal of Infectious Diseases 2019 Vol.9 (1):13-23 \\ DOI: http://dx.doi.org/10.4038/sljid.v9i1.8227
}

\begin{abstract}
Introduction: Biosynthesized silver nanoparticles (AgNPs) have good antimicrobial properties comparable to chemically synthesized silver nanoparticles. Further, they have good potential as antibiofilm agents.

Methods: AgNPs were synthesized from Pseudomonas aeruginosa (ATCC 27853), Escherichia coli (ATCC 25922), Staphylococcus aureus (ATCC 25923) and Acinetobacter baumannii (confirmed clinical isolate) and physically characterized by several techniques. The antibiofilm activity of the AgNPs against biofilms of P. aeruginosa, S. aureus and C. albicans was studied using crystal violet assay. Biofilms were formed in 96-well polystyrene plates and treated with biosynthesized AgNPs for 24 and $48 \mathrm{~h}$.

Results: AgNPs synthesized by all bacteria except S. aureus mediated AgNPs displayed 50\% biofilm inhibition at AgNP concentrations between $1.98-0.225 \mathrm{mg} / \mathrm{ml}$. S. aureus mediated AgNPs showed $50 \%$ biofilm inhibition only against $S$. aureus biofilm. Scanning Electron microscopic images indicated that biosynthesized AgNPs were able to decrease surface coverage of biofilms and to reduce the extracellular matrix causing morphological changes in biofilms noticeably.
\end{abstract}

Conclusion: This study reports the antibiofilm activity of bacteria mediated AgNPs. This is the first report on antibiofilm activity of AgNPs synthesized by Acinetobacter baumannii and also as a comparison of antibiofilm activity of several bacteria mediated AgNPs. According to the

${ }^{1}$ Department of Microbiology, Faculty of Medical Sciences, University of Sri Jayewardenepura, Sri Lanka
${ }^{2}$ Department of Chemistry, Faculty of Applied Sciences, University of Sri Jayewardenepura, Sri Lanka
${ }^{3}$ Centre for Plant Materials and Herbal Products Research, University of Sri Jayewardenepura, Sri Lanka Address for correspondence: Dr Chinthika P Gunasekara, Department of Microbiology, Faculty of Medical Sciences, University of Sri Jayewardenepura, Sri Lanka Telephone: +94718262860

Email: chinthika@sjp.ac.lk (D) https://orcid.org/0000-0002-6003-3088

Received 18 August 2018 and accepted 6 October 2018

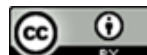

This an open-access article distributed under the terms of the Creative Commons Attribution License, which permits unrestricted use, distribution, and reproduction in any medium, provided the original author and source are credited. 
results, low dosages of green AgNPs can be applied in treating drug-resistant microbial infections in a cost effective manner. In conclusion, the bacterial synthesized AgNPs have antibiofilm activity and good stability suggesting its usefulness as economic and environmental friendly antibiofilm agents.

Keywords: Biofilms, Biosynthesis, Silver nanoparticles, Extracellular polysaccharides, Pseudo hyphae

\section{Introduction}

Bacterial biofilms pose a major challenge in medicine and are an important contributory factor towards the resistance of bacteria to antimicrobial treatment. Biofilms are a consortium of bacteria, fungi or other microorganisms which are embedded in a polysaccharide matrix where they can multiply, communicate with each other and persist, thus leading to biofilm infections specially associated with medical devices such as indwelling catheters ${ }^{1,2}$, contact lenses ${ }^{3}$ and prosthetic heart valves. ${ }^{4}$ Biofilms are responsible for disease outbreaks. Medically important biofilm forming pathogens include Staphylococcus aureus, Pseudomonas aeruginosa, Acinetobacter baumannii and Candida albicans.

It is a well-established fact that biofilm organisms show greater resistance to antibiotics. Further, the biofilm formation is affected by the level of mutations and quorum-sensing mechanisms which results in antibiotic resistance leading to more virulent strains. ${ }^{5}$ Biofilms are more difficult to be penetrated through the polysaccharide matrix by even high concentrations of antibiotics. These biofilms have defensive mechanisms against antibiotics and antifungals under adverse conditions. Therefore development of novel antibiofilm agents is important in combating biofilm related infections.

Nanoparticles are emerging as novel antimicrobial agents and are widely used in various applications. Metal nanoparticles such as silver (AgNPs) ${ }^{6,7}$, titanium dioxide $^{7}$ have been reported to be effective against some biofilm forming bacteria indicating their potential for future development as effective biofilmicidal agents. AgNPs show a broad spectrum of bactericidal effects. ${ }^{8}$ Martinez-Gutierrez ${ }^{9}$ reported the inhibition of biofilm formation by AgNPs as a strategy to contain biofilm formation in medical devices. Due to the cost of production and toxicity of chemically synthesized AgNPs, biosynthesis of AgNPs involving bacteria is being considered as an attractive alternative. Bacterial enzymes act as reducing agents of $\mathrm{Ag}^{+}$ions. ${ }^{10}$ Highly stable AgNPs can be produced from bacteria such as $P$. aeruginosa ${ }^{11}$ and Acinetobacter calcoaceticus. ${ }^{12}$

In this study we have investigated the potential antibiofilm ability of bacterial biosynthesized silver nanoparticles in vitro. 


\section{Materials and methods}

\section{Microbial cultures}

The bacterial strains $P$. aeruginosa (ATCC 27853), E. coli (ATCC 25922), S. aureus (ATCC 25923), A. baumannii (confirmed clinical isolate) and Candida albicans (ATCC 10231) were obtained from the culture collection (Bacteriology laboratory, Department of Microbiology) and cultivated in Nutrient Broth Medium.

Ag nanoparticle biosynthesis

P. aeruginosa (ATCC 27853), E. coli (ATCC 25922), A. baumannii (confirmed clinical isolate) and S. aureus (ATCC 25923) were cultured in Nutrient Broth Medium (Himedia, India) and incubated for $72 \mathrm{~h}$ at $37^{\circ} \mathrm{C}$ while shaking at $200 \mathrm{rpm}$. After the incubation period, the cultures were centrifuged at $6000 \mathrm{rpm}$ for $20 \mathrm{~min}$ and the supernatants were collected. ${ }^{10}$ Aqueous silver nitrate solution (1 M, Park, UK) was added into culture supernatants to prepare a final concentration of $0.4 \mathrm{~g} / \mathrm{l}$ and the mixture was kept at $60^{\circ} \mathrm{C}$ to induce $\mathrm{AgNP}$ formation.

Biosynthesis of AgNPs was confirmed by UV-Visible Spectrophotometry. The AgNPs were diluted ten times and UV Visible absorption was measured using a UV-Visible spectrophotometer (PerkinElmer Lambda 35, USA). Transmission Electron Microscopy (TEM) was used to determine the particle size distribution of AgNPs (JEOL JEM 2100, Japan).

Preparation of microbial biofilms

Preparation of standard cell suspension (1.0 McFarland standard)

Colonies of $24 \mathrm{~h}$ old cultures of $C$. albicans, $S$. aureus and $P$. aeruginosa were inoculated in Brain Heart Infusion broth (Himedia, India) separately and incubated at $37^{\circ} \mathrm{C}$ for $24 \mathrm{~h}$. After 24 $\mathrm{h}$ of incubation, cell pellets were harvested by centrifugation at $3000 \mathrm{rpm}$ for $10 \mathrm{~min}$. Cell pellets were washed twice with PBS. An optical density (OD) of 0.1 (corresponding to $1 \times 10^{8}$ cells $/ \mathrm{ml}$ ) was obtained at $595 \mathrm{~nm}$ (Multiskan EX, Thermo Scientific, USA) as the standard cell suspensions for each organism.

Formation of $48 \mathrm{~h}$ old biofilms

Two hundred microliters of standard cell suspensions were added into each well and incubated for $24 \mathrm{~h}$ at $37{ }^{\circ} \mathrm{C}$. After $24 \mathrm{~h}$ of incubation, $100 \mu \mathrm{l}$ of the medium was removed and the well was replenished with $100 \mu \mathrm{l}$ of fresh BHI medium followed by a further incubation at $24 \mathrm{~h}$ at $37{ }^{\circ} \mathrm{C}$.

\section{Assessment of biofilm formation}

To interpret the biofilm production ability of the selected pathogens, a standard criteria described by Stepanovic et al. ${ }^{13}$ was applied as follows. The optical density of the cut off was calculated based on the OD of the negative control. 
Optical density cut-off value (ODc) $=$ average OD of negative control (BHI only) $+3 \times$ standard deviation (SD) of negative control.

Average OD value

$\leq \mathrm{ODc} / \mathrm{ODc}<\sim \leq 2 \mathrm{x}$ ODc

$2 \mathrm{x}$ ODc $<\sim \leq 4 \mathrm{x}$ ODc

$>4 \mathrm{x}$ ODc

\section{Biofilm production}

Non/weak

Moderate

Strong

Determination of Inhibitory concentrations for 48 hour mature biofilms

The $48 \mathrm{~h}$ old mature biofilms were washed twice with sterile PBS. Then $100 \mu \mathrm{l}$ of serially diluted nanoparticle solutions were added into the corresponding wells in the microtiter plate. Negative control wells consisted of non-treated biofilms or sterile $\mathrm{BHI}$. $\mathrm{AgNO}_{3}(0.5 \% \mathrm{w} / \mathrm{v})$ treated biofilms were used as positive controls. The plates were incubated at $37{ }^{\circ} \mathrm{C}$ for $24 \mathrm{~h}$. The wells were washed twice with $200 \mu$ of sterile PBS gently to remove free floating planktonic bacteria and biofilm viability was determined using Crystal violet assay. The biofilms were fixed with $200 \mu \mathrm{l}$ of sodium acetate $(2 \% \mathrm{w} / \mathrm{v})$ and stained with $200 \mu \mathrm{l}$ of crystal violet dye $(0.1 \% \mathrm{w} / \mathrm{v})$. Excess stain was rinsed off by thorough washing with sterile distilled water and plates were allowed to dry. After drying, $200 \mu \mathrm{l}$ of $30 \%$ acetic acid was added into each well. The wells were incubated for $30 \mathrm{~min}$. Acetic acid was aspirated and transferred to a new plate. The absorbance was measured at $595 \mathrm{~nm}$ using an ELISA plate reader and the percentage of biofilm inhibition calculated using the following equation. The experiment was carried out in triplicate, the data averaged, and standard deviation calculated.

Percentage of biofilm inhibition $=\frac{\left(\mathrm{OD}_{595} \text { of untreated biofilm }-\mathrm{OD}_{595} \text { of treatedbiofilm }\right)}{\mathrm{OD}_{595} \text { of untreated biofilm }} \times 100$

\section{Scanning Electron Microscopy (SEM)}

The biofilms were cultured on $1 \mathrm{~cm}$ diameter sterile coverslips pretreated with conc. $\mathrm{H}_{2} \mathrm{SO}_{4}$ and absolute ethanol in 24 well culture plates (Corning, Germany) for $48 \mathrm{~h}$ and medium was replenished at $24 \mathrm{~h}$ of incubation. AgNPs were treated after 48 hours and further incubated for 24 $\mathrm{h}$ at $37^{\circ} \mathrm{C}$. Formed biofilms were fixed with $2.5 \%$ glutaraldehyde and washed with sterile PBS. Dehydration of samples was followed using an alcohol series $(30 \%, 50 \%, 60 \%, 70 \%, 80 \%, 90 \%$, $95 \%$ and absolute ethanol. After overnight drying in a desiccator, samples were coated with gold before imaging using a ZEISS EVO 18 Scanning Electron Microscope (Germany).

\section{Results}

The biosynthesis of AgNPs from all four bacteria were confirmed by the presence of narrow absorbance peaks observed approximately near $420 \mathrm{~nm}$ wavelength (Fig. 1). S. aureus mediated AgNPs gave a broad peak ranging from $420-450 \mathrm{~nm}$. 
According to TEM particle size analysis, all AgNPs were spherical in shape. The average sizes of the NPs were $11.14 \pm 6.59 \mathrm{~nm}(\mathrm{~S}-\mathrm{AgNPs}), 11.71 \pm 2.73 \mathrm{~nm}$ (P-AgNPs), $12.87 \pm 2.95 \mathrm{~nm}$ (EAgNPs) and $12.22 \pm 2.45 \mathrm{~nm}$ (A-AgNPs). Comparatively smaller AgNPs were produced by $S$. aureus and $P$. aeruginosa. Transmission electron microscopy identified all four AgNP species with average particle size $<20 \mathrm{~nm}$ in diameter suggesting the possibility of strong antimicrobial activity due to the small particle size.

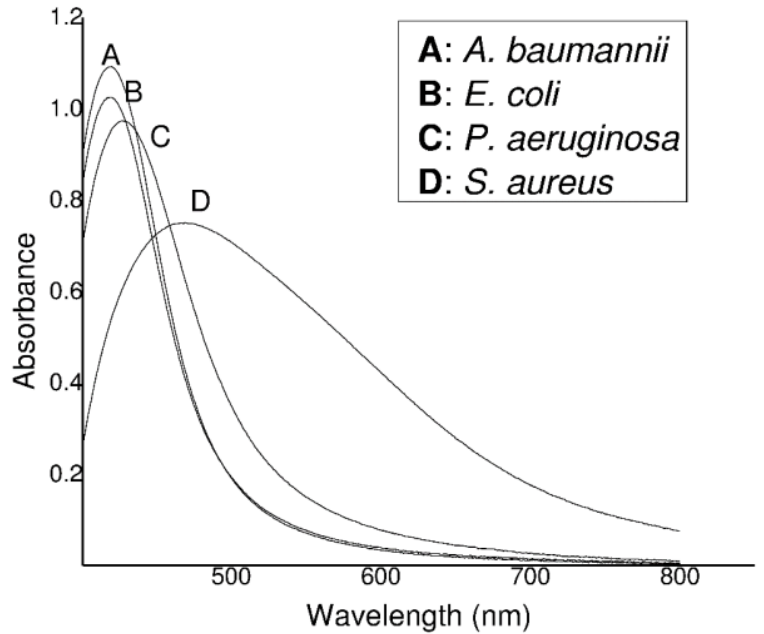

Fig. 1 UV-Visible absorption spectra of biosynthesized AgNPs

\section{Biofilm formation}

Biofilm formation of tested bacterial strains was determined using the crystal violet assay. Fig. 2 represents the biofilm formation assay at $24 \mathrm{~h}$ and $48 \mathrm{~h}$. All three organisms were found to form strong biofilms according to the criteria specified by Stepanović et al. ${ }^{13} P$. aeruginosa and $S$. aureus produced the strongest biofilms followed by $C$. albicans at both time points.

Bacterial biofilm formation was further confirmed using SEM imaging. Scanning electron microscopy
At the optimized conditions, the AgNP concentrations synthesized by $A$. baumannii (A-AgNPs) $(0.665 \mathrm{mg} / \mathrm{ml}), \quad$ E. coli (EAgNPs $)(0.99 \mathrm{mg} / \mathrm{ml}), \quad P$. aeruginosa $(\mathrm{P}-$ AgNPs) $(0.45 \mathrm{mg} / \mathrm{ml})$ and $S$. aureus (SAgNPs) $(0.435 \mathrm{mg} / \mathrm{ml})$ were calculated by obtaining the dry weight.
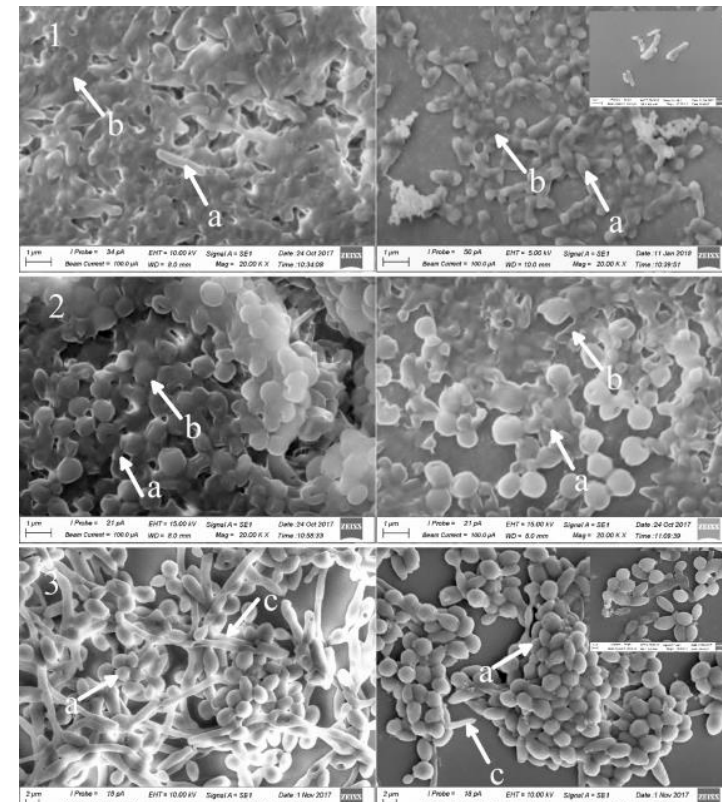

Fig. 2 SEM images of Biofilms of 1) P. aeruginosa, 2) S. aureus and 3) C. albicans Left: Before and Right: after treatment with AgNPs produced by S. aureus (a) cells, (b) extracellular matrix, (c) pseudo hyphae 
of $P$. aeruginosa and $S$. aureus biofilms demonstrated a network of thick extracellular matrix surrounding abundant bacterial cells which suggests biofilm formation. The biofilm architecture included presence of interconnecting thread like structures, possibly formed due to water channels between the biofilm embedded cells. $C$. albicans biofilms demonstrated budding oval yeast cells with extensive production of pseudo hyphae and presence of budding scars. (Fig. 2)

\section{Biofilm inhibition by AgNPs}

Serial dilutions of bacterial synthesized AgNPs were prepared and used to treat $24 \mathrm{~h}$ old bacterial biofilms. Biofilm treatment was carried out for $24 \mathrm{~h}$ and $48 \mathrm{~h}$. Highest inhibition of bacterial biofilms were observed at the highest tested AgNP concentrations of $1.33 \mathrm{mg} / \mathrm{ml}$ (A-AgNPs), $1.98 \mathrm{mg} / \mathrm{ml}$ (E-AgNPs), $0.9 \mathrm{mg} / \mathrm{ml}$ (P-AgNPs) and $0.87 \mathrm{mg} / \mathrm{ml}$ (S-AgNPs) at $24 \mathrm{~h}$ (Fig. 3).

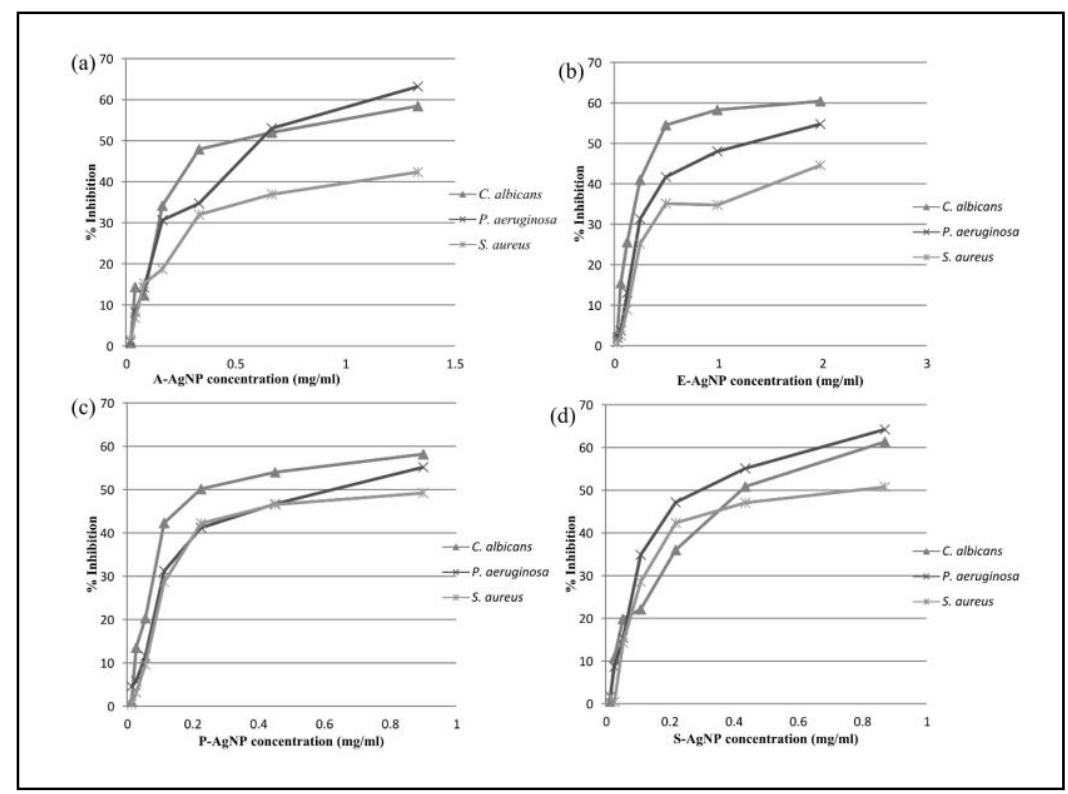

Fig. 3 Percentage inhibition of biofilms after $24 \mathrm{~h}$ treatment with the AgNPs produced by (a) A. baumannii, (b) E. coli, (c) P. aeruginosa and (d) S. aureus

Doubling dilutions of AgNPs were used to treat the $48 \mathrm{~h}$ old biofilms to determine $50 \%$ biofilm inhibitory concentration against the three bacterial biofilms tested. Biofilm inhibition was observed to be dose dependent. All four AgNPs showed more than 50\% of biofilm inhibition against biofilms formed by $P$. aeruginosa and $C$. albicans while $S$. aureus biofilms showed $50 \%$ inhibition at this concentration only when treated with S-AgNPs (Table 1). With regard to $S$. aureus biofilm inhibition, A-AgNPs at $1.33 \mathrm{mg} / \mathrm{ml}$ was able to inhibit $42 \%$ of the biofilms, while highest AgNP concentration tested for E-AgNPs $(1.98 \mathrm{mg} / \mathrm{ml})$ were able to inhibit $45 \%$ of the $S$. aureus biofilms (Fig. 3). Further, $49 \%$ biofilm inhibition was seen when treated with $0.9 \mathrm{mg} / \mathrm{ml}$, P-AgNPs. Fifty percent biofilm inhibition against $S$. aureus biofilms was achieved by treating the biofilms with $0.87 \mathrm{mg} / \mathrm{ml} \mathrm{AgNPs} \mathrm{biosynthesized} \mathrm{from} \mathrm{the} \mathrm{same} \mathrm{organism.}$ 
Table 1: Concentrations of green AgNPs showing more than 50\% inhibition of biofilms after 24 and $48 \mathrm{~h}$ treatments

\begin{tabular}{ccccccc}
\hline Biosynthesized & \multicolumn{5}{c}{$>50 \%$ Inhibitory concentrations of AgNPs $(\mathrm{mg} / \mathrm{ml})$} \\
\cline { 2 - 6 } AgNPs & \multicolumn{2}{c}{ C. albicans biofilms } & P. aeruginosa biofilms & S. aureus biofilms \\
\cline { 2 - 6 } & 24 h treated & 48 h treated & $\begin{array}{c}24 \mathrm{~h} \\
\text { treated }\end{array}$ & $\begin{array}{c}48 \mathrm{~h} \\
\text { treated }\end{array}$ & 24 h treated & 48 h treated \\
\hline A-AgNPS & 0.665 & 0.333 & 0.665 & 1.33 & - & 0.665 \\
E-AgNPS & 0.495 & 0.495 & 1.98 & 0.495 & - & - \\
P-AgNPS & 0.225 & 0.225 & 0.9 & 0.225 & - & 0.45 \\
S-AgNPS & 0.435 & 0.218 & 0.435 & 0.435 & 0.87 & 0.87 \\
\hline
\end{tabular}

The highest biofilm inhibition at 24 hours when treated with A-AgNPs was observed against $P$. aeruginosa biofilm (63\%) while treatment with E-AgNPs $(60 \%)$ and S-AgNPs $(61 \%)$ showed higher inhibition against $C$. albicans biofilms. $C$. albicans $(58 \%)$ had stronger inhibition when treated with P-AgNPs while S-AgNPs were able to inhibit P. aeruginosa (64\%), C. albicans $(61 \%)$ biofilms. The biofilm inhibitory concentrations resulting in $>50 \%$ biofilm inhibition by the four AgNPs after $24 \mathrm{~h}$ and $48 \mathrm{~h}$ of treatment against biofilms of C. albicans, $P$. aeruginosa and $S$. aureus. A-AgNP, E-AgNP, P-AgNP and S-AgNP are AgNPs biosynthesized using $A$. baumannii, E. coli, P. aeruginosa and S. aureus respectively. (Dashes indicate that the AgNPs did not give $>50 \%$ biofilm inhibition at the tested concentration).

Electron microscopic imaging revealed that treatment of $48 \mathrm{~h}$ old biofilms with AgNPs for $24 \mathrm{~h}$ resulted in visible cell destruction leading to reduction in cell number, reduced extracellular matrix and damaged cells in all bacterial biofilms. Based on the crystal violet assay, S-AgNPs was the most effective against all microorganisms tested (Fig. 3). Fig. 2 shows the SEM images of S-AgNPs against $P$. aeruginosa, $S$. aureus and $C$. albicans biofilms after $24 \mathrm{~h}$ of treatment. AgNP treated cells $(24 \mathrm{~h})$ had altered cell morphology and disruption of cell membranes were also visible. Presence of silver nanoparticles was confirmed by the EDAX spectrum. Blebbing of the cell surface was seen in some cells which indicate the apoptosis process in these cells. Treated biofilms had less extracellular matrix when in contact with AgNPs for $24 \mathrm{~h}$. After AgNP treatment of $C$. albicans biofilm, Candida cells showed rough outer cell wall with blebbing and markedly reduced presence of pseudo hyphae in AgNP treated specimens, while microcolonies were still present. The AgNPs were seen attached to the surface of the yeast cells.

\section{Discussion}

Bacterial biofilm formation is a challenge in treatment of infections due their intrinsic antimicrobial resistance. Thus, control of biofilm formation is critical in management of biofilm mediated infections. Silver nanoparticles have been reported to have multiple properties leading to antimicrobial activity and biofilm inhibition.

The nanoparticle size is a critical factor in determination of antimicrobial and antibiofilm properties $^{8}$. According to Morones et al. ${ }^{8}$, AgNPs less than $10 \mathrm{~nm}$ of size can directly contact with bacterial cells and enhance antimicrobial activity. The nanoparticles reported in this study 
had an average particle size of $<20 \mathrm{~nm}$ and had a spherical morphology. The smaller size of the nanoparticles can increase the antimicrobial potency due to the higher surface to volume ratio which facilitates greater interaction with the cell surface. Nanoparticles with small size have superior penetrating ability. ${ }^{8}$

The appearance, size, shape and particle distribution depend on surface plasmon resonance energy of AgNPs. ${ }^{14}$ Further characterization of biosynthesized AgNPs using FT-IR spectroscopy indicated $\mathrm{NH}$ stretch vibrations present in the amide linkages of primary and secondary amines of proteins, presence of nitrocompounds from proteins or enzymes, $\mathrm{C}-\mathrm{H}$ symmetrical stretch vibration of alkanes and $-\mathrm{C}-\mathrm{N}$ - stretching vibrations confirming that the attached proteins in the biosynthesized AgNPs support stabilization of AgNPs. ${ }^{15}$

In the present study, silver nanoparticles synthesised by all four bacterial species demonstrated over $50 \%$ biofilm inhibition at a AgNP concentration between $1.98 \mathrm{mg} / \mathrm{ml}$ to $0.225 \mathrm{mg} / \mathrm{ml}$ (Fig. 3). The antibiofilm effectiveness of the AgNPs in the present study shows good promise when used at lower concentrations of approximately $1 \mathrm{mg} / \mathrm{ml}$ as seen in this study. Several studies have determined the effective biofiom inhibitory concentration of AgNPs. Martinez-Gutierrez et al. ${ }^{9}$ demonstrated strong biofilm inhibition against Pseudomonas and Acinetobacter biofilms while weaker biofilm inhibitory activity was observed against MRSA and Candida albicans biofilms using high AgNP concentrations ranging from $500-1000 \mathrm{mg} / \mathrm{ml}$. In contrast, a study by Barapatre et al. ${ }^{14}$ using biosynthesized AgNPs $(100 \mathrm{~nm})$ had a minimum bactericidal concentration (MBC) of AgNPs between $16 \mu \mathrm{g} / \mathrm{ml}$ to $64 \mu \mathrm{g} / \mathrm{ml}$ against $S$. aureus, E. coli and $P$. aeruginosa. These differences may be due to the multiple factors contributing to the antimicrobial properties of the nanoparticles including the source of the AgNP, culture and biosynthesis parameters used, nanoparticle size and shape, surface charge, concentration, test organism and biofilm forming ability.

Biofilm formation is dependant on a number of factors and cell signalling through quorum sensing is one of the critical factors involved. AgNPs are involved in quorum quenching thereby diminishing the cell signalling as demonstrated by Chaudhari et al. ${ }^{16}$ against $S$. aureus biofilms. Further, AgNPs may arrest the synthesis of exopolysaccharides (EPS) which is an essential pre-requirement for biofilm formation. ${ }^{17}$ A study by Chandra et al. ${ }^{2}$, demonstrated the three phases (early, intermediate and maturation) of biofilm formation of $C$. albicans using SEM imaging at different time points. The early phase of biofilm formation lacked detectable matrix, in the intermediate phase, cell density increased and formation of microcolonies was observed after $11 \mathrm{~h}$ while the mature biofilms were seen to have abundant matrix. The exopolysaccharides play an important role in protecting the biofilm from desiccation and antimicrobial agents. ${ }^{18}$ Further, EPS helps in cell adhesion and facilitates cell to cell communication. EPS also has a role in cell organization and contributes to structural integrity of the biofilm. Therefore targeting the EPS can be a useful approach in biofilm control. In the present study and in studies by others, the treatment of AgNPs to bacterial biofilms induced several structural changes as observed in the SEM images. Reduction in the biofilm associated EPS was observed for all the four test organisms comparable to other reported studies indicating the arrest of biofilm EPS secretion. The attachment of AgNPs to the surface of microbial cells 
was observed in this study using SEM and has also been reported by several groups. ${ }^{17,19}$ Oza et al. ${ }^{20}$ reported that the antibacterial effect of AgNPs may be due to penetration of released Ag ions in bcterial cell wall. AgNPs can disrupt the cell wall and rapidly detach the biofilms. Further, AgNPs can cause the formation of reactive oxygen species (ROS) which inhibits the antioxidant defense system and causes mechanical damage to the cell membrane. ${ }^{21}$ The overall antibiofilm activity of AgNPs may therefore occur by several mechanisms.

In the present study, AgNPs biosynthesized from different bacterial species were able to inhibit the bacteial and Candida biofilms. An interesting observation was, that against the $S$. aureus biofilms, the most effective AgNP was the NPs synthesized by $S$. aureus itself. Among the Gram negative bacterial biofilms tested, S-AgNPs were also found to be strongly effective against $C$. albicans and $P$. aeruginosa biofilms compared to other AgNPs synthesized. Especially in $P$. aeruginosa biofilms treated with AgNPs, the morphology change was visible with increased roughness, as reported previously for $E$. coli ${ }^{17}$, suggesting cell membrane damage by AgNPs. Comparable to previously published studies using planktonic cells, S. aureus biofilms were more resistant to AgNPs compared to Gram negative bacterial biofilms ${ }^{11,22}$. The structure of the cell wall can influence the adhesion and penetration of the nanomaterial into the cell. Electron microscopic studies suggest that the higher cell wall thickness of Gram positive bacteria compared to the Gram negative bacterial cell wall may act as a barrier to the penetration of the nanoparticles into the cell. ${ }^{23}$ Thus Gram positive bacterial cells posess an intrinsic resistance to the antimicrobial activity of nanoparticles compared to Gram negative bacteria as seen in this study and studies published by others. ${ }^{11,22,24}$

Recently the focus on natural "green" methods of nanoparticle synthesis has been on the increase considering the low cost and environment friendly approach of biosynthesis compared to the chemical and physical methods of nanoparticle production. In this study, the focus was to compare different AgNPs biosynthesized by four bacterial species and to determine their antibiofilm potential. Using well defined culture and biosynthesis conditions in all experiments, it was possible to obtain AgNPs with reproducible properties which was confirmed by UVvisible spectroscopy, TEM, SEM and other methods. The exact mechanism of biofilm inhibition by green AgNPs is not fully understood.

\section{Conclusion}

The AgNPs synthesized by bacteria had significant antibiofilm activity after $24 \mathrm{~h}$ exposure against Gram positive, Gram negative and Candida biofilms at low concentrations displaying morphological changes and reduced biomass. The duration of AgNP exposure was important to obtain higher inhibitory effect. The results suggest the potential of green AgNPs as antibiofilm agents in therapeutics.

\section{Abbreviations}

AgNPs: Silver nanoparticles

EPS: Extracellular polysachcharides

MBC: Minimum bactericidal concentration 
A-AgNPs: AgNPs by A. baumannii

E-AgNPs: AgNPs by E. coli

P-AgNPs: AgNPs by P. aeruginosa

S-AgNPs: AgNPs by $S$. aureus

\section{Acknowledgement}

The authors wish to thank the University of Sri Jayewardenepura, Sri Lanka for providing financial support (ASP/01/RE/MED/2016/42) and laboratory facilities.

\section{References}

1. Seddiki S, Boucherit-Otmani Z, Boucherit K, et al. Fungal infectivities of implanted catheters due to Candida sp. Biofilms formation and resistance. J Mycol Med. 2015; 25(2):130-135. doi: https://doi.org/10.1016/j.mycmed.2015.03.003

2. Chandra J, Kuhn DM, Mukherjee PK, et al. Biofilm formation by the fungal pathogen Candida albicans: development, architecture, and drug resistance. J Bacteriol. 2001; 183(18):5385-5394. doi: http://dx.doi.org/10.1128/JB.183.18.5385-5394.2001

3. Imamura Y, Chandra J, Mukherjee PK, et al. Fusarium and Candida albicans biofilms on soft contact lenses: model development, influence of lens type, and susceptibility to lens care solutions. Antimicrob Agents. Chemother. 2008; 52(1):171-182.

doi: http://dx.doi.org/10.1128/AAC.00387-07

4. Peters G, Locci R, Pulverer G. Microbial colonization of prosthetic devices. II. Scanning electron microscopy of naturally infected intravenous catheters. Zentralbl Bakteriol, Mikrobiol Hyg B. 1981;173(5):293-299. PMID:6792814

5. Hoiby N, Bjarnsholt T, Givskov, et al. Antibiotic resistance of bacterial biofilms. Int J Antimicrob agents. 2010; 35(4):322-332. doi: http://dx.doi.org/10.1016/j.ijantimicag.2009.12.011

6. Goswami SR, Sahareen T, Singh M, et al. Role of biogenic silver nanoparticles in disruption of cell-cell adhesion in Staphylococcus aureus and Escherichia coli biofilm. Ind Eng Chem Res. 2015; 26:73-80. doi: http://dx.doi.org/10.1016/j.jiec.2014.11.017

7. Naik K, Kowshik M. Anti-quorum sensing activity of $\mathrm{AgCl}-\mathrm{TiO}_{2}$ nanoparticles with potential use as active food packaging material. $J$ Appl Microbiol. 2014;117(4):972-983. doi: https://doi.org/10.1111/jam.12589

8. Morones JR, Elechiguerra JL, Camacho A, et al. The bactericidal effect of silver nanoparticles. Nanotechnology. 2005; 16(10):2346. doi: http://dx.doi.org/10.1088/0957-4484/16/10/059

9. Martinez-Gutierrez F, Boegli L, Agostinho A, et al. Anti-biofilm activity of silver nanoparticles against different microorganisms. Biofouling. 2013; 29(6):651-660.

doi: http://dx.doi.org/10.1080/08927014.2013.794225

10. Jeevan P, Ramya K, Rena AE. Extracellular biosynthesis of silver nanoparticles by culture supernatant of Pseudomonas aeruginosa. Ind J Biotechnol. 2012; 11(1):72-76. No doi

11. Paul D, Sinha SN. Extracellular Synthesis of Silver Nanoparticles Using Pseudomonas aeruginosa KUPSB12 and Its Antibacterial Activity. Jordan J Biol Sci. 2014; 7(4):245-250. doi: http://dx.doi.org/10.12816/0008246

12. Singh R, Wagh P, Bellare J. Synthesis, optimization, and characterization of silver nanoparticles from Acinetobacter calcoaceticus and their enhanced antibacterial activity when combined with antibiotics. International journal of nanomedicine. 2013; 8:4277-4290.

doi: https://dx.doi.org/10.2147\%2FIJN.S48913 
13. Stepanović S, Vuković D, Hola V, et al. Quantification of biofilm in microtiter plates: overview of testing conditions and practical recommendations for assessment of biofilm production by staphylococci. Apmis. 2007; 115(8):891-899.

doi: http://dx.doi.org/10.1111/j.1600-0463.2007.apm_630.x

14. Barapatre A, Aadil KR, Jha H. Synergistic antibacterial and antibiofilm activity of silver nanoparticles biosynthesized by lignin-degrading fungus. Bioresour Bioprocess. 2016; 3(1):1. doi: http://dx.doi.org/10.1186/s40643-016-0083-y

15. Peiris MMK, Fernando SSN, Jayaweera PM, et al. Comparison of Antimicrobial Properties of Silver Nanoparticles Synthesized from Selected Bacteria. Indian J Microbiol. 2018; 58(3):301311. doi: 10.1007/s12088-018-0723-3

16. Chaudhari PR, Masurkar SA, Shidore VB, et al. Effect of biosynthesized silver nanoparticles on Staphylococcus aureus biofilm quenching and prevention of biofilm formation. Nano-Micro Lett. 2012; 4(1):34-39. doi: http://dx.doi.org/10.1007/BF03353689

17. Ansari MA, Khan HM, Khan AA, et al. Antibiofilm efficacy of silver nanoparticles against biofilm of extended spectrum $\beta$-lactamase isolates of Escherichia coli and Klebsiella pneumoniae. Appl Nanosci. 2014; 4(7):859-868.

doi: http://dx.doi.org/10.1007/s13204-013-0266-1

18. Flemming H-C, Wingender J, Szewzyk U, et al. Biofilms: an emergent form of bacterial life. Nat Rev Microbiol. 2016; 14(9):563. doi: http://dx.doi.org/10.1038/nrmicro.2016.94

19. Lara HH, Romero-Urbina DG, Pierce C, et al. Effect of silver nanoparticles on Candida albicans biofilms: an ultrastructural study. J nanobiotechnology. 2015;13(1):91.

doi: http://dx.doi.org/10.1186/s12951-015-0147-8

Oza G, Pandey S, Shah R, et al. Extracellular fabrication of silver nanoparticles using Pseudomonas aeruginosa and its antimicrobial assay. Pelagia Res Lib Adv Appl Sci Res. 2012; 3:1776-1783. No doi

20. Liao J, Mo AC, Wu HK, et al. Antibacterial activity of silver-hydroxyapatite/titania nanoparticles on oral bacteria. In Key Engineering Materials. Trans Tech Publ: 2007: 299-302. doi: http://dx.doi.org/10.4028/www.scientific.net/KEM.330-332.299

21. Peiris MK, Gunasekara CP, Jayaweera PM, et al. Biosynthesized silver nanoparticles: are they effective antimicrobials? Mem Inst Oswaldo Cruz. 2017;112(8):537-543. doi: http://dx.doi.org/10.1590/0074-02760170023

22. Singh M, Mallick A, Banerjee M, et al. Loss of outer membrane integrity in Gram-negative bacteria by silver nanoparticles loaded with Camellia sinensis leaf phytochemicals: plausible mechanism of bacterial cell disintegration. Bulletin of Materials Science. 2016; 39(7):1871-1878. doi: http://dx.doi.org/10.1007/s12034-016-1317-5

23. Senarathna U, Fernando S, Gunasekara $\mathrm{T}$, et al. Enhanced antibacterial activity of $\mathrm{TiO}_{2}$ nanoparticle surface modified with Garcinia zeylanica extract. Chem Cent J. 2017; 11(1):1-7. doi: http://dx.doi.org/10.1186/s13065-017-0236-x 